\title{
A Comparison of Needle Types and Biopsy Techniques used in Liver Biopsies of Chronic Hepatitis B Patients
}

\author{
Erdal KARAVAŞ1, Faruk KARAKEÇILI2, Mecdi Gürhan BALCl3 \\ ${ }^{1}$ Erzincan Binali Yıldırım University Faculty of Medicine, Department of Radiology, Erzincan, Turkey \\ 2Erzincan Binali Yıldırım University Faculty of Medicine, Departments of Infectious Diseases and Clinical Microbiology, Erzincan, Turkey \\ ${ }^{3}$ Erzincan Binali Yıldırım University Faculty of Medicine Department of Pathology, Erzincan, Turkey
}

\begin{abstract}
Objectives: To investigate the effect on pathological evaluation of the biopsy technique used in percutaneous liver biopsies applied with semi-automatic 16 gauge (G) and 18G Tru-cut and Menghini aspiration needles in patients with chronic hepatitis $\mathrm{B}(\mathrm{CHB})$.

Materials and Methods: The study included 104 cases diagnosed with CHB applied with liver biopsy between 2013-2018. The pathology results of biopsies were evaluated with the Menghini technique under ultrasound(USG) guidance (n:26), and with 16G (n:54) and 18G (n:24) semi-automatic Tru-cut needles under USG.

Results: The fibrosis score in 5 (9.3\%) of the $16 \mathrm{G}$ cases and in 3 (12.5\%) of the $18 \mathrm{G}$ cases, and the ISHAK score in 3 (5.6\%) of the $16 \mathrm{G}$ and in 1 (4.2\%) of the $18 \mathrm{G}$ cases could not be determined. There was no significant difference between the methods and needle types in terms of the number of pieces, number of portal sites, fibrosis and ISHAK score(p>0.05). There was a statistically significant difference between the biopsies performed with Menghini method and tru-cut method with $16 \mathrm{G}$ and $18 \mathrm{G}(\mathrm{p}<0.0001)$ in terms of material length. The diagnosis rates for the Menghini technique, and $16 \mathrm{G}$ and $18 \mathrm{G}$ Tru-cut needles were $100 \%, 90.7 \%$ and $83.3 \%$, respectively, with no statistically significant difference determined ( $p>0.05$ ).

Conclusion: Although a larger tissue piece is obtained with the Menghini technique, allowing evaluation of a larger portal area, no significant difference was determined between the techniques in the pathological evaluation. Taking patient safety and comfort into consideration, Tru-cut needle biopsy under USG guidance is recommended rather than the Menghini technique as less trauma is created.

Keywords: Chronic hepatitis B, Liver, Biopsy, Technique, Needle.
\end{abstract}

\section{Introduction}

Liver biopsy has been performed since the end of the 19th century. Paul Ehrlich (Germany) performed liver biopsy for the first time in 1883, and Sheila Sherlock described percutaneous biopsy technique in 1945 (1, 2). Menghini performed biopsy with aspiration technique in 1958 (3). The first ultrasound (US) guided biopsy was performed in 1972 (4). Today, despite technological advancements such as US, computed tomography (CT) and magnetic resonance imaging (MRI), liver biopsy is still recognized as the gold standard method in order to establish the diagnosis, to evaluate the prognosis and to plan the treatment $(5,6)$.

Major indications for liver biopsy include liver neoplasm, cholestatic liver disease, presence of abnormal hepatic function tests, chronic viral hepatitis, unexplained jaundice, or evaluation of suspicious drug reactions. In addition, liver biopsy is performed to evaluate rejection or to plan treatment in liver transplantation, and to confirm the diagnosis and prognosis in diffuse liver diseases $(7,8)$. Whereas contraindications for liver biopsy divided into two as absolute and partial. Absolute contraindications include noncooperative patients, severe bleeding disorder (INR > 1.6, platelet count $<50,000$ ), Infection of the hepatic bed, and extrahepatic biliary obstruction, while partial contraindications are abdominal ascites, cyst hydatid, vascular lesions, amyloidosis and morbid obesity $(8,9)$. The most common complications following liver biopsy are pain and hemorrhage. Among the other rarely seen complications are pneumothorax, hemothorax, organ perforations, biliary peritonitis, infections, and hemobilia $(8,10)$.

Liver biopsy is performed using three different methods as percutaneous, transvenous (transjugular, transfemoral) and surgical-laparoscopic biopsy. There are three different methods for percutaneous biopsies as palpation/percussion, radiologic marking, and real time imaging guidance $(11,12)$. Aspiration (Menghini,

Address for Correspondence: Erdal Karavaş MD, Erzincan Binali Yıldırım University Faculty of Medicine, Department of Radiology, Erzincan, Turkey

Phone:+90 5327335754 E-mail: erdalkaravas@hotmail.com ORCID ID: orcid.org/0000-0001-6649-3256 Received: 15/12/2018 Accepted: 11/01/2019

${ }^{(C)}$ Copyright 2019 by Viral Hepatitis Society / Viral Hepatitis Journal published by Galenos Publishing House. 
Jamshidi, Klatskin) needles, manual (Vim-Silverman) or full/semiautomatic tru-cut needles are used as the biopsy needle $(8,11)$. Technique and needle selection may vary depending on personal experience of the physician, type of approach or biopsy indication.

In this study, we aimed to compare liver biopsy techniques performed in patients with chronic hepatitis $\mathrm{B}(\mathrm{CHB})$ and needle selection. Accordingly, we compared US guided real time biopsy technique performed with with semi-automatic 16 gauge $(G)$ and 18G tru-cut needles and percutaneous liver biopsy carried out with Menghini (aspiration) needles and investigated the effects of methods used and needle selection on pathologic evaluation.

\section{Materials and Methods}

A total of 104 patients diagnosed with $\mathrm{CHB}$ and undergone liver biopsy in Erzincan Binali Yildirim University Medical Faculty between 2013 and 2018 were retrospectively examined and included in the study. This study was approved by Erzincan Binali Yildirim University Ethics Committee with 104 numbered decision, and informed consent forms were received from the patients. Coagulation tests were studied in all patients before biopsy procedure, and biopsy performed after impaired parameters were improved in patients with a risk for bleeding. The same US device (GE Logiq P5, Korea, Sangdaewon-don; 1.6-4.5 MHz convex transducer) was used for guidance in all procedures. In biopsies performed with Menghini needle, patients were assessed with US before the procedure to determine and mark the most appropriate site of biopsy. Similarly, patients were evaluated with US before the procedure in biopsies performed with tru-cut needles. The most appropriate position and biopsy site for the patients were determined. None of the patients received sedation. In all patient, operation site was cleaned with $10 \%$ povidone iodine and after waiting for one minute, skin antisepsis was made with $72 \%$ alcohol. Local anesthesia (Prilocain, Citanest, AstraZeneca, Germany) was then applied. A small incision was made in entry site of the needle. The probe was worn a sterile sheath in the cases of tru-cut needles. 18G Menghini (Bard Magnum, Bard Peripheral Vascular Inc. AZ, USA) needles were used in aspiration technique, while $16 \mathrm{G} 15 \mathrm{~cm}$ or $18 \mathrm{G} 15 \mathrm{~cm}$ semi-automatic tru-cut needles (Geotek Semi-Automatic Biopsy Needle, Ankara, Turkey) were used in the real time application. Biopsy was repeated in the case of a sample length $<0.5 \mathrm{~cm}$. The samples were kept in formalin and evaluated by a pathologist experienced in hepatology. ISHAK scoring, material length, the number of viewed periportal sites, and fibrosis stage were determined for the obtained samples.

We compared and evaluated adequacy of biopsy material for histopathologic evaluation, number of pieces, rate of diagnosis, length of the obtained material, number of portal sites, and rate of complications between the methods and needle types used.

\section{Statistical Analysis}

Results of continuous variables were expressed as mean \pm standard deviation, and median (min-max), while categorical variables were given as " $n$ " and percentage (\%). Pearson's Chi-square and Fisher Exact tests were used for the analysis of categorical variables. Normality of the variables was tested when statistically significant difference between the groups was analyzed. T test for independent groups was used in comparisons of two independent groups. One way variance analysis was used to compare more than two groups. Appropriate test was used for post hoc evaluation. $p<0.05$ values were considered statistically significant. Data were analyzed using IBM SPSS v. 19 (IBM Corp. Released 2010. IBM SPSS Statistics for Windows Version 19.0 Armong, NY, IBM Corp.) package software.

\section{Results}

In our study, 104 patients diagnosed with $\mathrm{CHB}$ and undergone liver biopsy were evaluated. Biopsies performed with Menghini technique $(n=26)$ by marking with US and those performed with US guidance using $16 \mathrm{G}(\mathrm{n}=54)$ and $18 \mathrm{G}(\mathrm{n}=24)$ semi-automatic tru-cut needles were compared. The mean age was $40.16 \pm 14.95$ (range: 17-78) years. Of all patients 66 were male and 38 female (Table 1). No statistically significant difference was found between the groups in terms of age and gender ( $p>0.05)$.

Biopsy procedure was repeated due to the biopsy material length $<5 \mathrm{~mm}$ in biopsies performed with 16G $(\mathrm{n}=1)$ and 18G $(n=1)$. The mean material length of both methods and procedures performed with three needles was found as $23.03 \mathrm{~mm} \pm 8.91$ with Menghini needles, $10.15 \mathrm{~mm} \pm 3.57$ with $16 \mathrm{G}$ tru-cut needle, and $12.00 \mathrm{~mm} \pm 3.35$ with $18 \mathrm{G}$ Tri-cut needle (Figure 1). There was a statistically significant difference between the biopsies performed with Menghini method and tru-cut method with 16G $(p<0.0001)$ and $18 \mathrm{G}(\mathrm{p}<0.0001)$ in terms of material length. No statistically significant difference was found between $16 \mathrm{G}$ and $18 \mathrm{G}$ needles in the biopsies performed with tru-cut method in terms of material length ( $p>0.05)$.

When number of material pieces were examined; the mean piece number was found as $1.08 \pm 0.27$ with Menghini needle, $1.09 \pm 0.29$ with $16 \mathrm{G}$ tru-cut needle and $1.17 \pm 0.38$ with $18 \mathrm{G}$ tru-cut needle. No significant difference was found between the methods in terms of the number of pieces ( $p>0.05$ ).

When the number of portal sites of the material taken in the biopsies performed with both methods and three needles were compared; the number of portal sites was found as $\geq 6$ in

\begin{tabular}{|c|c|c|c|c|c|c|c|}
\hline \multirow[t]{2}{*}{ Needle } & \multirow{2}{*}{$\begin{array}{l}\text { Sex } \\
\text { Female }\end{array}$} & \multirow[b]{2}{*}{ Male } & \multicolumn{5}{|l|}{ Age } \\
\hline & & & $\mathbf{N}$ & Mean & SD & Minimum & Maximum \\
\hline 18G Tru-cut & 9 & 15 & 24 & 36.17 & 15.58 & 18 & 71 \\
\hline 16G Tru-cut & 18 & 36 & 54 & 41.89 & 15.15 & 18 & 78 \\
\hline
\end{tabular}


all biopsies with Menghini needle, $5.80 \pm 0.92$ with $16 \mathrm{G}$ tru-cut needle and $5.92 \pm 0.88$ with $18 \mathrm{G}$ tru-cut needle (Table 2). There was no significant difference between the methods and needle types in terms of the number of portal sites ( $p>0.05)$.

Fibrosis score $(100 \%)$ was determined in the histopathologic examination of all biopsy materials obtained with Menghini method. Fibrosis score could not be determined in $5(9.3 \%)$ patients biopsied with $16 \mathrm{G}$ tru-cut needle and 3 (12.5\%) patients biopsied with 18G tru-cut needle (Table 3). No statistically significant difference was found between the groups in terms of the determination of fibrosis score ( $p>0.05)$.

ISHAK score $(100 \%)$ was determined in the histopathologic examination of all biopsy materials obtained with Menghini method. Fibrosis score could not be determined in 3 (5.6\%) patients biopsied with $16 \mathrm{G}$ tru-cut needle and 1 (4.2\%) patient biopsied with $18 \mathrm{G}$ tru-cut needle. No statistically significant difference was found between the groups in terms of the determination of ISHAK score $(p>0.05)$.

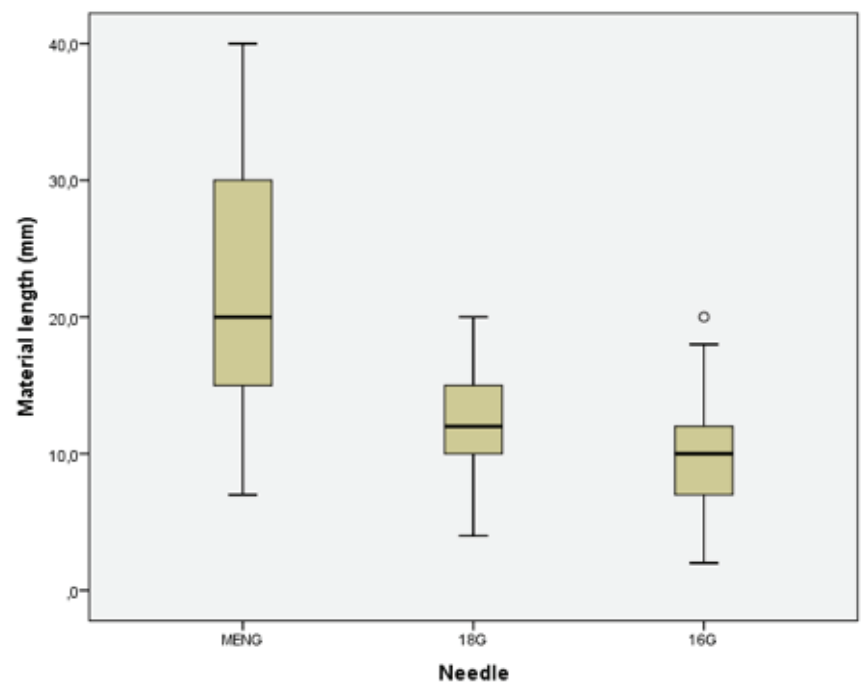

Figure 1. Relationship of material length and needle selection in patients undergone biopsy
Material sufficient for histopathologic evaluation could be obtained in all patients biopsied with Menghini technique, with a diagnosis rate found as $100 \%$. Whereas, biopsy material was not sufficient for histopathologic evaluation in 7 (8.97\%) biopsies performed with $16 \mathrm{G}$ and $18 \mathrm{G}$ tru-cut needles and diagnosis could not be established. The rate of diagnosis was found as $90.7 \%$ and $83.3 \%$ in liver biopsies performed with semi-automatic $16 \mathrm{G}$ and $18 \mathrm{G}$ tru-cut needles, respectively. No statistically significant difference was found between the methods and needles in terms of the rate of diagnosis in histopathologic evaluation with the obtained material ( $p>0.05)$.

\section{Discussion}

Percutaneous biopsy is a widely used interventional procedure for tissue sampling. Imaging methods is a safe tool in access of the needle to the target (13-15). The first preferred guide method is US guided liver biopsy because of its advantages such as evaluation of the parenchyma, imaging of gallbladder, ability to distinguish intrahepatic main vascular structures with Doppler, not exposing patients to radiation, and being inexpensive, easy to use and portable. In addition, real time imaging is another advantage of US guided biopsy $(15,16)$. Percutaneous biopsies using imaging methods have largely prevented complications of blind biopsy and unnecessary operations $(10,13)$. The rate of complication is $1 \%-5 \%$ and the rate of mortality is $0.01 \%-0.009 \%$ in percutaneous liver biopsy (17). There are studies reporting that Menghini and tru-cut biopsy techniques have no superiority on each other in terms of complications, although there are publications reporting more pain with Menghini method (18-20). Negative pressure created by nature of the technique in blind biopsies performed with Menghini method is thought to cause more pain at follow up after biopsy (21). In our study none of the patients developed major complication. This was thought to be resulted from small number of our patients and experience of the practitioner. Comparison of complications among three groups was not included in the study as number of complications was low.

There are many studies in the literature evaluating liver biopsy related complications and sufficiency of establishing diagnosis with

Table 2. Statistical findings of needle selection and number of portal sites in patients undergone biopsy

\begin{tabular}{|c|c|c|c|c|c|c|}
\hline Needle & N & Mean & SD & Minimum & Maximum & p \\
\hline Menghini & 26 & 6.00 & 0.00 & 6 & 6 & \multirow[t]{2}{*}{$>0,05$} \\
\hline 16G Tru-cut & 54 & 5.80 & 0.92 & 2 & 8 & \\
\hline Total & 104 & 5.88 & 0.78 & 2 & 8 & \\
\hline
\end{tabular}

G: Gauge, SD: Standard Deviation

Table 3. Needle selection and rate of fibrosis determination in patients undergone biopsy

\begin{tabular}{|l|l|l|l|l|}
\hline Needle & Not determined & Determined & Total & $\mathbf{p}$ \\
\hline Menghini & 0 & 26 & 26 & $>0,05$ \\
\hline $16 \mathrm{G}$ Tru-cut & 5 & 49 & 54 \\
\hline 18G Tru-cut & 3 & 21 & 24 & 104 \\
\hline Total & 8 & 96 & & \\
\hline G: Gauge & \multicolumn{5}{|l|}{} \\
\hline
\end{tabular}


different techniques and needles of different thickness. However, we could not find a study comparing diagnostic material sufficiency specifically between Menghini and tru-cut biopsy needle in patients with $\mathrm{CHB}(6,22-25)$.

Quality of liver biopsy is usually determined with length, width, fragmentation and complete portal routes (26). Quality of a liver biopsy sample plays an important role in evaluation of grade and stage of liver disease in patients with $\mathrm{CHB}$. Length of the material obtained with biopsy is thought to be one of the most important factors affecting success chance in establishing the diagnosis (11, $23,27)$. Today, number of portal sites is thought to be important for a reliable grading and staging. In general, it is accepted that the most appropriate liver biopsy sample must be $20-25 \mathrm{~mm}$ in length and must have more than 11 portal sites $(28,29)$. Whereas some studies have reported that materials of $15 \mathrm{~mm}$ in length with at least 6-8 portal sites are sufficient for the evaluation (30). In the present study, we considered 6 and more portal sites as sufficient for evaluation.

In our study, material length was statistically significantly higher in the biopsies performed using Menghini technique compared to those performed with tru-cut method. However, no significant difference was found in comparisons made for determination of portal sizes, ISHAK scoring or fibrosis.

Although there are studies stating that it is possible to grading chronic hepatitis with $19 \mathrm{G}$ and thinner needles, the use of thick cutting needles is recommended in diffuse liver diseases $(24,31)$. Since we considered that the risk of obtaining insufficient tissue with thin needles in biopsies, we preferred 16-18G. In our study, rates of diagnosis with $16 \mathrm{G}$ and $18 \mathrm{G}$ needles were $90.7 \%$ and $83.3 \%$, respectively, and no statistically significant difference was found between the needles in terms of establishing the diagnosis. However, our rate of diagnosis was lower compared to the studies in the literature $(25,32)$.

Percutaneous biopsies have become safer and more efficient with innovations in needle designs and technological advancements in imaging modalities (15).

Persons without experience on liver aspiration biopsy are more likely to obtain high-quality samples with fully automatic tru-cut biopsy needles $(15,33,34)$. Higher-quality tissue samples are obtained with automatic biopsy needles compared to aspiration needles in patients with advanced fibrosis or cirrhosis. Therefore, it has been stated that automatic needles should be preferred in terms of suspicious advanced fibrosis or cirrhosis (35).

\section{Study Limitation}

Data about biopsy complications were insufficient because of the retrospective design of the study, and relatively lower number of patients compared to the similar studies.

\section{Conclusion}

In our study rates of diagnosis in liver biopsies performed with $16 \mathrm{G}$ and $18 \mathrm{G}$ tru-cut biopsies was partially lower compared to the literature. Much more portal sites could be evaluated with Menghini technique compared to the other method since longer tissue pieces were obtained with this technique. Therefore, there was no insufficient sample in biopsies performed with this technique. However, no statistically significant difference was found between this method and the other two methods in terms of pathologic evaluation. Given safety and comfort of the patient, we recommended to use US guided tru-cut biopsy rather than Menghini technique, which causes more traumas.

\section{References}

1. von Frerichs F. Uber den Diabetes. Berlin: Hirschwald, 1884.

2. Sherlock S. Aspiration Liver Biopsy. The Lancet. 1945;246:397401

3. Menghini G. One-second needle biopsy of the liver Gastroenterology. 1958;35:190-9.

4. Rasmussen SN, Holm HH, Kristensen JK, et al. Ultrasonicallyguided Liver Biopsy. Bmj. 1972;2:500-02.

5. Afyon M. Liver Biopsy is the Gold Standard at Present, How about Tomorrow? Viral Hepatit Dergisi. 2016;22:67-68.

6. Kose S, Ersan G, Tatar B, et al. Evaluation of Percutaneous Liver Biopsy Complications in Patients with Chronic Viral Hepatitis. Eurasian J Med. 2015;47:161-4.

7. Castera L. Hepatitis B: are non-invasive markers of liver fibrosis reliable? Liver Int. 2014;34 Suppl 1:91-6.

8. Rockey DC, Caldwell SH, Goodman ZD, et al. Liver biopsy. Hepatology. 2009;49:1017-44.

9. Atwell TD, Smith RL, Hesley GK, et al. Incidence of bleeding after 15,181 percutaneous biopsies and the role of aspirin. AJR Am J Roentgenol. 2010;194:784-9.

10. Piccinino F, Sagnelli E, Pasquale G, et al. Complications Following Percutaneous Liver Biopsy A Multicentre Retrospective Study on 68276 Biopsies. Journal of Hepatology. 1986;2:165-73.

11. Al Knawy B, Shiffman M. Percutaneous liver biopsy in clinical practice. Liver Int. 2007;27:1166-73.

12. Rossi P, Sileri P, Gentileschi P, et al. Percutaneous Liver Biopsy Using an Ultrasound-Guided Subcostal Route. Digestive Diseases and Sciences. 2001;46:128-32.

13. Bret PM, Fond A, Casola G, et al. Abdominal lesions: a prospective study of clinical efficacy of percutaneous fine-needle biopsy. Radiology. 1986;159:345-6

14. Kwan SW, Bhargavan M, Kerlan RK, Jr., et al. Effect of advanced imaging technology on how biopsies are done and who does them. Radiology. 2010;256:751-8.

15. Akpinar IN, Kuzan TY. Perkütan Biyopsi: Igne Secimi ve Görüntüleme Kilavuzlari. Türk Radyoloji Seminerleri. 2015;3:15968.

16. Arıbas BK, Ünlü DN, Dingil G, et al. Yarı-otomatik 16 Gauge Tru-cut Iğne ile Perkütan Karaciğer Biyopsileri. Van Tıp Dergisi. 2010;17:69-76.

17. Güner R, Baykam N. Which One Should Be Prefered: Liver Biopsy or Non-Invasive Procedures? Viral Hepatit Dergisi. 2017;23(3):63-4.

18. Gilmore IT, Burroughs A, Murray-Lyon IM, et al. Indications, methods, and outcomes of percutaneous liver biopsy in England and Wales: an audit by the British Society of Gastroenterology and the Royal College of Physicians of London. Gut. 1995;36:43741.

19. Colombo M, Ninno Ed, Franchis Rd, et al. Ultrasound-Assisted Percutaneous Liver Biopsy: Superiority of the Tru-Cut Over the Menghini Needle for Diagnosis of Cirrhosis. Gastroenterology. 1988;95.

20. García Ordoñez MA, Antúnez Gálvez JM, Aguilar Heredia Y, et al. Percutaneous liver biopsy: comparative study on the efficacy of and tolerance to the automatic tru-cut technique. Anales de medicina interna. 1996;13:419-22. 
21. Karacaer Z, Yilmaz Karadağ F, Durmuş G, et al. Percutaneous Liver Needle Biopsy Methods Can Be Safe and Effective in Patients with Viral Hepatitis. Viral Hepatit Dergisi. 2017;23:65-70.

22. Tuna N, Yahyaoglu M, Öztürk G, Öğütlü $A$, Utku AÇ, Durmaz $Y$, et al. Karaciğer Biyopsisi Deneyimi. Viral Hepatit Dergisi. 2012;18(2):115-9

23. Turhan V, Acar A, Küçükodaci Z, et al. Evaluation of 1380 Percutaneous Blind Liver Needle Biopsies Performed in Patients With Chronic Viral Hepatitis. Viral Hepatit Dergisi. 2009;14:57-62.

24. Rocken $\mathrm{C}$, Meier H, Klauck $\mathrm{S}$, et al. Large-needle biopsy versus thin-needle biopsy in diagnostic pathology of liver diseases. Liver International. 2001;21:391-97.

25. Cakmakci E, Caliskan KC, Tabakci ON, et al. Percutaneous liver biopsies guided with ultrasonography: a case series. Iran J Radiol. 2013;10:182-4.

26. Bravo AA, Sheth SG, Chopra S. Liver biopsy. N Engl J Med. 2001;344:495-500.

27. Bedossa P, Dargere D, Paradis V. Sampling variability of liver fibrosis in chronic hepatitis C. Hepatology. 2003;38:1449-57.

28. Colloredo G, Guido M, Sonzogni A, et al. Impact of liver biopsy size on histological evaluation of chronic viral hepatitis: the smaller the sample, the milder the disease. Journal of Hepatology. 2003;39:239-44.

29. Cholongitas E, Senzolo M, Standish R, et al. A Systematic Review of the Quality of Liver Biopsy Specimens. American Journal of Clinical Pathology. 2006; 125: 710-21.

30. Grant A, Neuberger J. Guidelines on the use of liver biopsy in clinical practice. British Society of Gastroenterology. 1999; 45 Suppl: IV1-IV11.

31. Petz $D$, Klauck $S$, Rohl FW, et al. Feasibility of histological grading and staging of chronic viral hepatitis using specimens obtained by thin-needle biopsy. Virchows Arch. 2003;442:238-44.

32. Sezgin O, Altintas E, Ucbilek E, et al. Percutaneous Liver Biopsies: Safety and Efficacy. J Med Sci. 2010;30:1287-91.

33. Moulton JS, Moore PT. Coaxial percutaneous biopsy technique with automated biopsy devices: value in improving accuracy and negative predictive value. Radiology. 1993;186:515-22.

34. Gazelle GS, Haaga JR. Biopsy needle characteristics. Cardiovasc Intervent Radiol. 1991;14:13-6.

35. Sherman KE, Goodman ZD, Sullivan ST, et al. Liver biopsy in cirrhotic patients. Am J Gastroenterol. 2007;102:789-93. 